\title{
Medical problems of adults who were sexually abused in childhood
}

\author{
R P Arnold, D Rogers, D A G Cook
}

Fromeside Clinic, Glenside Hospital, Bristol BS16 1DD R P Arnold, MRCPSYCH, senior registrar

Burden Neurological Hospital, Bristol

D Rogers, MRCPSYCH, consultant neuropsychiatrist

Department of Mental Health, University of

Bristol, Bristol

D A G Cook, MRCPSYCH, senior lecturer

Correspondence to:

Dr R P Arnold, consultant psychiatrist, Glenside Hospital, Bristol BS16 1DD.

BrMed f 1990;300:705-8

\begin{abstract}
The aim of the study was to see whether adults who had been sexually abused in childhood were vulnerable to physical symptoms and therefore investigation and intervention.

The case histories of seven patients who were aged 22-39, were under the care of three consultant psychiatrists, had experienced childhood sexual abuse, and had a history of medical or surgical intervention were surveyed. The patients had had a mean of 18 contacts with non-psychiatric consultant teams and a mean of eight operations, with a high rate $(66-70 \%)$ of normal findings. They had experienced many somatic symptoms, which led to investigations and interventions in the specialties of gynaecology, obstetrics, gastroenterology, urology, rheumatology, haematology, orthopaedics, neurology, and neuropsychiatry. The history of childhood sexual abuse was recognised only in the later stages of this medical and surgical intervention.

The possibility of childhood sexual abuse should be considered earlier in such cases to prevent further unnecessary intervention.
\end{abstract}

\section{Introduction}

Published work on the prevalence of childhood sexual abuse has been growing, ${ }^{1}$ but up to $98 \%$ of such abuse probably remains unreported. ${ }^{2}$ Childhood sexual abuse does not necessarily lead to long term

TABLE I-Details of patients and childhood sexual abuse

\begin{tabular}{ccccclc}
\hline $\begin{array}{c}\text { Case } \\
\text { No }\end{array}$ & Sex & $\begin{array}{c}\text { Age } \\
\text { (years) }\end{array}$ & $\begin{array}{c}\text { Age at onset of } \\
\text { abuse (years) }\end{array}$ & $\begin{array}{c}\text { Duration of abuse } \\
\text { (years) }\end{array}$ & Abuser & Nature of abuse \\
\hline 1 & F & 39 & 8 & 7 & Father & Full coitus \\
2 & F & 35 & 6 & 10 & Father & Full coitus \\
3 & F & 22 & 14 & 3 & Father & Full coitus \\
4 & F & 35 & 14 & 3 & Stepfather's friend & Full coitus \\
5 & F & 38 & 10 & 4 & Father & Full coitus \\
6 & F & 27 & 10 & Father & Full coitus \\
7 & F & 21 & 13 & Friend of family & Full coitus \\
\hline
\end{tabular}

*Once; abuser committed suicide one month later.

tTwice; abuser remained in contact for four vears with threats.

TABLE II -Contacts with health service of seven patients who were sexually abused in childhood

\begin{tabular}{|c|c|c|c|c|c|c|c|c|c|}
\hline & \multicolumn{7}{|c|}{ Case No } & \multirow[b]{2}{*}{ Total } & \multirow[b]{2}{*}{ Mean } \\
\hline & 1 & 2 & 3 & 4 & 5 & 6 & 7 & & \\
\hline \multicolumn{10}{|l|}{ Consultant teams involved: } \\
\hline Non-psychiatric & 26 & 35 & 14 & 19 & 8 & 14 & 11 & 127 & 18 \\
\hline Psychiatric & 7 & 9 & 8 & 4 & 3 & 3 & 3 & 37 & 5 \\
\hline \multicolumn{10}{|l|}{ Admissions: } \\
\hline Total & 29 & 42 & 62 & 16 & 10 & 23 & 26 & 208 & 30 \\
\hline Psychiatric (including overdoses) & 8 & 14 & 46 & 4 & 1 & 4 & 10 & 87 & 12 \\
\hline Operations & 10 & 12 & 1 & 10 & 8 & 6 & 7 & 54 & 8 \\
\hline General anaesthetics & 12 & 13 & 1 & 11 & 8 & 6 & 7 & 58 & 8 \\
\hline Thickness of available notes $(\mathrm{cm})$ & 10 & 17 & 12 & 8 & 4 & 9 & 8 & 68 & 10 \\
\hline \multicolumn{10}{|l|}{ Age (years) at first: } \\
\hline Operation & 13 & 26 & 14 & 23 & 10 & 13 & 13 & 112 & 16 \\
\hline Recorded major illness & 13 & 8 & 14 & 23 & 10 & 13 & 13 & 94 & 13 \\
\hline $\begin{array}{l}\text { Psychiatric contact } \\
\text { Pas }\end{array}$ & 13 & 23 & 17 & 21 & 37 & 26 & 20 & 157 & 22 \\
\hline Time between first medical contact and identification of abuse (years) & 22 & 26 & 5 & 10 & 26 & 13 & 8 & 110 & 16 \\
\hline Time since first psychiatric contact (years) & 26 & 11 & 4 & 14 & 1 & 1 & 1 & 57 & 8 \\
\hline
\end{tabular}

TABLE III-Specialties concerned in contacts with health service of seven patients who were sexually abused in childhood

\begin{tabular}{|c|c|c|c|c|c|c|c|c|}
\hline & \multicolumn{7}{|c|}{ Case No } & \multirow[b]{2}{*}{ Total } \\
\hline & 1 & 2 & 3 & 4 & 5 & 6 & 7 & \\
\hline Breast surgery & + & & & & + & & & 2 \\
\hline Cardiology & & + & + & & & & & 2 \\
\hline Cosmetic surgery & & & & + & & & + & 2 \\
\hline Dermatology & + & & & + & + & & & 3 \\
\hline Ear, nose, and throat & + & + & & + & & & & 3 \\
\hline Endocrinology & & & & + & & & & 1 \\
\hline Gastroenterology & + & + & + & + & + & + & + & 7 \\
\hline General medicine & + & + & + & + & + & + & + & 7 \\
\hline General surgery & + & + & + & + & + & + & + & 7 \\
\hline Gynaecology & + & + & + & + & + & + & & 6 \\
\hline Haematology ${ }^{\star}$ & & & & + & & & & 1 \\
\hline Neurology & + & + & + & & + & & + & 5 \\
\hline Neurosurgery & + & + & & & & + & & 3 \\
\hline Obstetrics & + & + & & & + & & & 3 \\
\hline Pain clinic & + & & & & & + & & 2 \\
\hline Psychiatry & + & + & + & + & + & + & + & 7 \\
\hline Orthopaedics & & + & & + & + & + & & 4 \\
\hline Rheumatology & + & + & & & & & & 2 \\
\hline Urology & + & + & & + & & + & & 4 \\
\hline Total & 14 & 13 & 7 & 12 & 10 & 9 & 6 & $71^{\star}$ \\
\hline
\end{tabular}

${ }^{\star}$ Mean $=10$.

maladjustment, but persistent psychological problems such as disturbances of sexual function and adjustment, personality disorder, alcohol and drug misuse, eating disorders, attempted suicide, and depression have been described. ${ }^{3}$ Research on long term vulnerability to physical symptoms has been less extensive, frequently going unremarked, ${ }^{4}$ and has concentrated on somatisation and pelvic pain. We conducted a survey of adult psychiatric patients with a history of childhood sexual abuse to see whether some were particularly vulnerable to physical investigation and intervention, including surgery.

\section{Patients, methods, and results}

We asked three consultant adult psychiatrists to report to us on any patient seen during the previous 12 months who had experienced full sexual intercourse under the age of 16 with an adult. Seven women fitted these criteria (table I). As rates of childhood sexual abuse of $33 \%$ and $44 \%^{6}$ have been reported among female psychiatric patients this almost certainly represents underreporting.

Full medical and psychiatric histories, particularly details of specialist referrals, investigations, and operations, were obtained from the hospital case notes. When a patient had been seen in a hospital outside the three districts studied and few details were available we recorded the minimum results. For example, when a patient was known to have had a laparotomy elsewhere we assumed that she had been admitted under one surgical team. Tables II and III show the extent and nature of contacts that the seven patients had had with hospital services.

Investigations reported in the case notes were recorded, including those such as biopsy and endoscopy that required general anaesthesia. Investigations not 
reported in the hospital case notes, because they were lost or performed by general practitioners or at other health facilities, were not included. Our results (table IV) therefore probably underestimate the total number of investigations performed.

Table $\mathrm{V}$ lists the operations undergone by the patients. To estimate how many of the operations had been necessary and how many might have been performed in response to psychological distress we sought objective evidence of indications for surgery. The criterion was the presence of objectively measured signs or abnormal pathological results whether macroscopic or microscopic. Caesarean sections, terminations of pregnancy, and one case of cosmetic surgery to remove a hairy naevus were difficult to classify, and a second total which excludes them is also shown in table V. Caesarean sections were performed for six out of eight live births, the indication being hyperemesis gravidarum or prolonged labour caused by uncoordinated uterine contractions. A psychological component has been proposed for each of these indications. ${ }^{\text {i }}$

The range of psychiatric diagnoses noted in these patients is shown in table VI. Suicide attempts were not well documented in medical case notes, neither were histories of previous attempts that had not led to admission. The numbers given are therefore estimates. The persistent second person auditory hallucinations described by two patients resembled those described in post-traumatic stress disorder ${ }^{9}$ rather than those previously described in patients with psychotic illnesses and histories of childhood sexual abuse. ${ }^{10}$

\section{Case history}

One of the seven patients was a 39 year old nurse currently taking prolonged sickness leave. She had no family history of psychiatric disorder. Her mother died when she was 10 , and when her grandmother died she had to take responsibility for her younger siblings. Her father, who drank heavily and beat her frequently, made sexual advances towards her which escalated to full intercourse when she was 13. She had a normal appendix removed at that time.

When she was 15 her father remarried and stopped sexually abusing her. After this she lived unhappily

TABLE IV - Numbers of investigations in seven patients who were sexually abused in childhood

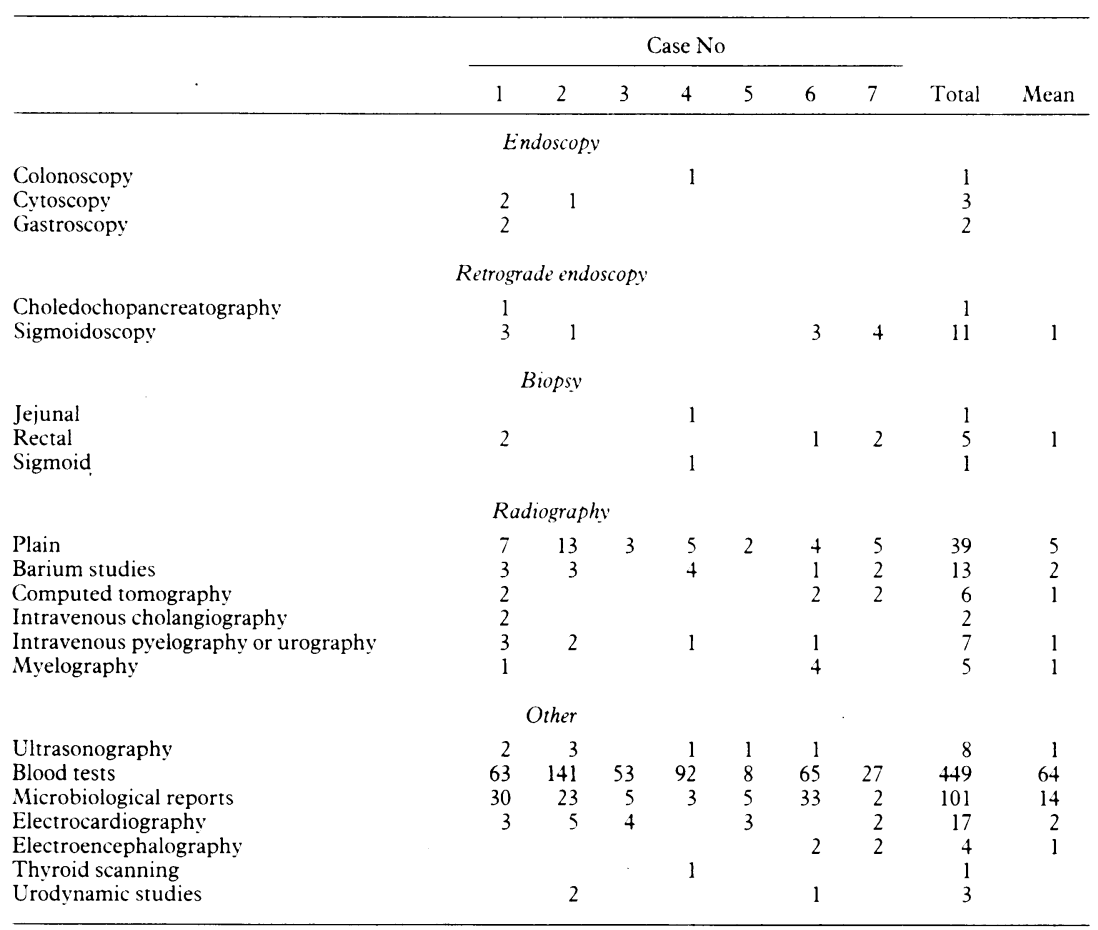

TABLE $\mathrm{V}-$ Numbers of operations and of abnormal or objective findings in seven patients who were sexually abused in childhood

\begin{tabular}{lcc}
\hline & & $\begin{array}{c}\text { Abnormal } \\
\text { or } \\
\text { objective } \\
\text { findings }\end{array}$ \\
\hline Anal: & Total & \\
$\quad$ Sphincterotomy & 1 & 1 \\
Stretch & 1 & 0 \\
Appendicectomy & 3 & 0 \\
Arthroscopy & 1 & 1 \\
Caesarean section & $6^{\star}$ & 0 \\
Cholecystectomy & 2 & 1 \\
Cosmetic surgery & 6 & 6 \\
Dental clearance & 1 & 1 \\
Dilatation and curettage & 9 & 2 \\
Hysterectomy & 4 & 0 \\
Ileostomy & 1 & 0 \\
Internal fixation of fracture & 1 & 1 \\
Laminectomy & 1 & 1 \\
Laparoscopy & 4 & 1 \\
Laparotomy & 2 & 1 \\
Mobilisation under anaesthetic (knee) & 1 & 0 \\
Proctocolectomy & 1 & 0 \\
Removal of cervical stump and bilateral oophorectomy & 1 & 0 \\
Reversal of sterilisation & 1 & 0 \\
Revision of ileostomy & 1 & 0 \\
Sterilisation & 1 & 0 \\
Termination of pregnancy & 3 & 0 \\
Tonsillectomy & 1 & 0 \\
Transfer of patellar tendon & 1 & 0 \\
\hline Total & 54 & 16 \\
Total excluding doubtful casest & 44 & 15 \\
\hline & &
\end{tabular}

$\star$ Out of eight live births.

†Caesarean sections, terminations of pregnancy, and one case of cosmetic surgery to remove hairy naevus.

TABLE VI-Numbers of psychiatric diagnoses and findings in seven patients who were sexually abused in childhood

\begin{tabular}{|c|c|c|c|c|c|c|c|c|}
\hline & \multicolumn{7}{|c|}{ Case No } & \multirow[b]{2}{*}{ Total } \\
\hline & 1 & 2 & 3 & 4 & 5 & 6 & 7 & \\
\hline \multicolumn{9}{|c|}{ Diagnoses } \\
\hline Alcohol abuse & + & + & + & & & & & 3 \\
\hline $\begin{array}{l}\text { Anxiety } \\
\text { Depression }\end{array}$ & $\begin{array}{l}+ \\
+\end{array}$ & + & + & + & + & + & $\begin{array}{l}+ \\
+\end{array}$ & $\frac{2}{7}$ \\
\hline Eating disorder & & + & + & + & & & & 3 \\
\hline Hysterical dissociative reaction & + & + & & & & & + & 3 \\
\hline Other diagnosis entailing hysteria & + & + & & + & & + & & 4 \\
\hline $\begin{array}{l}\text { Personality disorder } \\
\text { Substance abuse }\end{array}$ & + & + & $\begin{array}{l}+ \\
+\end{array}$ & & & & + & $\begin{array}{l}4 \\
1\end{array}$ \\
\hline \multicolumn{9}{|c|}{ Findings } \\
\hline Suicide attempts & 25 & 30 & 60 & 1 & 0 & 2 & 6 & $124^{\star}$ \\
\hline Self mutilation to relieve tension & & & + & & & & + & $\begin{array}{l}1 \\
2\end{array}$ \\
\hline Second person voice hallucinations & & & & + & & & + & 2 \\
\hline
\end{tabular}

${ }^{\star}$ Mean $=18$

with an aunt, but despite this she enjoyed school and left with three $\mathrm{O}$ levels. At 17 she became pregnant and left home to marry. Her first and second children were delivered by caesarean section because of uncoordinated uterine activity and prolonged labour. Her third birth was by elective caesarean section, and she was sterilised at the same time.

From the age of 19 she was investigated by gynaecologists, urologists, and gastroenterologists for persistent abdominal pain and for a range of associated symptoms including urinary incontinence and rectal bleeding. Interventions included cystoscopy, intravenous pyelography, dilatation and curettage, and a laparotomy that proceeded to cholecystectomy. A series of small gall stones and a duplex kidney and ureter were the only abnormalities found. The conclusion that the duplex kidney was not the cause of her symptoms was repeatedly recorded. No physical cause could be found for many of her reported symptoms.

At 23 she began seeing psychiatrists and was admitted to psychiatric hospitals on several occasions with diagnoses of depression, anxiety, and hysterical dissociative states. Four years later while obtaining a divorce she took several overdoses, and her husband gained custody of the children. She showed little 
interest in using psychiatric help to work through her problems.

She continued to have physical problems over the next 10 years. She had recurrent severe otitis externa and vertigo. A surgeon reluctantly reversed her sterilisation when she remarried at 31 . Abdominal pain persisted despite subtotal hysterectomy and was subsequently investigated by gastroscopy, barium meal examination, ultrasonography, computed tomography, rectal biopsy, cystoscopy, and intravenous pyelography. All these investigations yielded negative results, and the irritable bowel syndrome was diagnosed.

She is currently incapacitated by back pain, which began when she was 37 . A myelogram showed slight intervertebral bulging, suggesting mild disc prolapse. A laminectomy "primarily for the worrying symptoms" did not provide relief for long, and her condition relapsed with neurological symptoms that were "of a distribution which did not equate with any possible anatomical lesion." During that readmission to hospital her history of childhood sexual abuse was revealed when a nurse heard her talking about it in her sleep. She was referred to a neuropsychiatrist and admitted to a psychiatric unit. Exploration of her childhood experiences was accompanied by a slow but steady improvement in her mobility, but once mobile she took two overdoses in the ward. For the past two years she has not felt sufficiently free from back pain to return to work.

\section{Discussion}

To our knowledge no one has previously described the quantity of medical investigation and intervention that can be associated with childhood sexual abuse. An association between such abuse and somatisation (hysteria) has been described." Accounts of physical symptoms associated with childhood sexual abuse have described abdominal pain, headache, backache, and unspecified somatisation in the general population. . $^{12-15}$ Briere and Runtz found that 41 out of 278 undergraduate students reported childhood sexual abuse and had a significantly higher rate of somatisation than students who had not been abused. ${ }^{14}$ Morrison compared two groups of women who were matched for race, age, and educational attainment: 60 had primary somatisation disorder and 31 had primary affective disorders. ${ }^{15}$ Those with somatisation had a significantly higher rate of childhood sexual abuse. Neither the paper by Briere and Runtz nor the paper by Morrison specified symptoms.

Raskin described 50 patients with chronic pelvic pain of whom $10 \%$ had demonstrable organic disease and $35 \%$ had experienced incest. ${ }^{16}$ Walker et al found a history of childhood sexual abuse in 16 out of 25 women $(64 \%)$ with pelvic pain compared with seven out of 30 women $(23 \%)$ with infertility or presenting for tubal ligation. ${ }^{17}$ The group with pelvic pain also had a significantly higher rate of major depression. Both groups had similar rates of organic disease.

We suggest that childhood sexual abuse may have been an aetiological factor in the development of physical symptoms in the patients we studied, although we recognise that causality is difficult to prove. Incest often occurs with other disturbances in family relationships that may themselves be aetiological factors. Four of the patients had unambiguous histories of severe family problems in childhood, including parental death, severe marital discord, and violence (one patient was systematically tortured by her mother). One father committed suicide when threatened with disclosure of his behaviour. The brothers of two of the patients had also been sexually abused, in one case by the mother.
Our patients had also been through many disturbing experiences as adults. Although six had had sustained heterosexual relationships, only one was in such a relationship at the time of the study, and she had been divorced once. Two patients had experienced further abuse in the form of rape. The child of one patient died of the sudden infant death syndrome. Whatever the relevance of these other factors, it is important that a history of childhood sexual abuse is uncovered so that the patient can be offered specific help.

Adults who report incest may be describing fantasies, as suggested by Freud, but his conclusions were hypothetical and have been criticised. ${ }^{18}$ Some researchers have been able to obtain independent evidence and have confirmed reported abuse. ${ }^{219}$ In the absence of objective evidence we believe the accounts of sexual abuse of the patients we studied to be accurate because the reports were often obtained unexpectedly by staff who were not seeking such information and patients seemed to gain little from making them. The primary therapists found the accounts consistent and convincing. The sexual intention of non-invasive contacts may be a misinterpretation influenced by fantasy. The sexual motivation of vaginal or anal intercourse (to which we limited our study) is irrefutable.

The context of childhood sexual abuse may influence its effects. The extent of psychological trauma reported varies with the relationship to the abuser, with the nature, duration, cultural context, and emotional experience of the abuse, and with associated violence..$^{20}$ Using these criteria our group represented more severely traumatised patients and is not representative of all cases of childhood sexual abuse. Our patients suffered severe and prolonged childhood sexual abuse, and in adulthood they were investigated and treated extensively and expensively with minimal relief of distress. The emotional cost to these patients and their increased exposure to the risks of anaesthesia, surgery, and other interventions were considerable.

These patients had common features that may help to identify other abused adults. They had had abdominal operations or severe illnesses in childhood, and some of their persistent symptoms in adulthood were of similar character. They had all seen numerous consultants and had had multiple medical and surgical investigations for symptoms that were difficult to assess objectively. Though the youngest patient with disturbed behaviour readily aroused suspicion of underlying psychological problems, the others had often presented at times when they seemed to be socially stable. Six had had prolonged heterosexual relationships, three of them in marriages that produced children. Though depression and deliberate self harm were common, they often postdated surgery and had not been present at the time of referral. Eisendrath et al suggested that persistent abdominal pain may be caused by psychological factors when the patient has past evidence of somatisation, a friend or relative with similar problems, prominent guilt, and a history of physical abuse by a parent or spouse. ${ }^{21}$

When suspicion of childhood sexual abuse has been aroused health care professionals should have a strategy to follow."2 A full social history and mental state examination should be recorded and discussed with the general practitioner. The general practitioner is a vital link in reducing multiple referral and in pursuing appropriate psychological support. There should be few circumstances in which issues of confidentiality outweigh this. It was striking that the medical and surgical case notes of the patients we studied contained almost no psychosocial details, even when the suspicion of emotional disturbance had become overwhelming. One patient reported childhood sexual abuse at an early consultation, but brief mention 
of this was buried in a thick file of case notes. Patients who do not report histories of childhood sexual abuse spontaneously do so with surprising willingness when questioned directly, ${ }^{5}$ and an interview with a female social worker is a particularly suitable strategy..$^{23}$

Patients like those we have studied present a particular challenge to psychiatry because they are often difficult to help. Guilt, alienation, and despair are often deep ${ }^{12}$ and lead to resistance against psychiatric intervention. Direct confrontation about symptoms that cannot be assessed objectively may destroy any chance of a therapeutic relationship. We found that psychiatric help coincided with a temporary reduction in the rate of physical investigations but failed to prevent a gradual relapse of symptoms. Therefore, while referral to a psychiatrist is appropriate, general practitioners, physicians, and surgeons must forestall further referral, investigation, and intervention. Once the pattern has been identified such interventions should be contemplated only in the light of objectively measurable signs or the probability of disease occurring that threatens life or health. Intervention solely to alleviate symptoms should be resisted.

We thank Dr Glin Bennet for permission to report on two of his patients, and Mrs Joan Sparks for help in the literature search.

1 Markowe HLJ. The frequency of childhood sexual abuse in the UK. Health Trends 1988; Feb:2-6.

2 Russell DEH. The secret trauma: incest in the lives of girls and women. New York: Basic Books, 1986

West DJ. Incest in childhood and adolescence: long term effects and therapy. Br f Hosp Med 1988;40:352-60.
4 Mrazek D, Mrazek P. Child maltreatment. In: Rutter RM, Hertzov L, eds. Child and adolescent psychiatry. Oxford: Blackwell Scientific, 1985:691-3. 5 Rosenfeld AA. Incidence of a history of incest among 18 female psychiatric patients. Am f Psychiatry 1979;136:791-5.

6 Gold ER. Long-term effects of sexual victimization in childhood: an attributional approach. $\mathcal{F}$ Consult Clin Psychol 1986;54:471-5.

7 Wuitchik M, Bakal D, Lipshitz J. The clinical significance of pain and cognitive activity in latent labor. Obstet ( ivnecol 1989;73:35-42.

LaFerla JJ. Psvchologic and behavioral factors in hyperemesis gravidarum. Am $\mathcal{F}$ Obstet Gynecol 1988;159:532-3.

9 Burges Watson IP, Hoffman L, Wilson GV. The neuropsichiatry of post-traumatic stress disorder. Brf Psychiutry 1988:152:164-73.

10 Ellenson GS. Detecting a history of incest: a predictive syndrome. Social Casework 1985:66:525-32.

11 Cohen ME, Robins E, Purtell JJ, Altman MW, Reid DE. Excessive surgery in hysteria: study of surgical procedures in 50 women with hysteria and 190 hysteria: study of surgical proce

12 Sedney MA, Brooks B. Factors associated with a history of childhood sexual experience in a non-clinical female population. Fournal of the American Academy of Child Psychiatry 1984;23:215.

13 Lindberg FH, Distad LJ. Post traumatic stress disorders in women who experienced childhood incest. Child Abuse Negl 1985;9:329.

14 Briere J, Runtz. M. Symptomatology associated with childhood sexual victimization in a non-clinical adult sample. Child Abuse Negl 1988:12:51-9. 5 Morrison J. Childhood sexual histories of women with somatisation disorder. Am O Psychiatry 1989;146:239-41.

16 Raskin D. Diagnosis in patients with chronic pelvic pain. Am f Psychiatry 1984;141:824.

17 Walker E, Katon W, Harrop-Griffiths J, Holm L, Russo J, Hickok LR. Relationship of chronic pelvic pain to psychiatric diagnosis and childhood Relations

18 Rosenfeld AA, Nadelson CC, Kreiger M, Backman JH. Incest and sexual abuse in children. Fournal of the American Academy of Child Psychiatry

19 Herman JL, Schatzow E. Recovery and verification of memories of childhood sexual trauma. Psychoanalytic Psychology 1987;4:1-14

20 Brown A. Initial and long-term effects: a review of the research, In: Finkelhor $\mathrm{D}$, ed. A sourcebook on childhood sexual abuse. Beverly Hills, California: Sage, 1986:165-75.

21 Eisendrath SJ, Way LW, Ostroff JW, Johanson CA. Identification of psychogenic abdominal pain. Psychosomatics 1986;27:705-12.

22 Bachmann GA, Moeller TP, Benett J. Childhood sexual abuse and the consequences in adult women. Childhood Sexual Abuse 1988;71:631-41.

23 Caldirola D, Gemperle MB, Guzinski GM, Gross RJ, Doerr H. Incest and pelvic pain: the social worker as part of a research team. Health Soc Work 1983;3:309-19.

(Accepted 19 January 1990)
Biomedical Sciences

Research Centre

University of Ulster,

Jordanstown, County

Antrim BT37 0QB

M B E Livingstone, MSC,

lecturer

J J Strain, PHD, senior

lecturer

M E Barker, PHD, nutritionist

PG McKenna, PHD, professor

MRC Dunn Nutrition Unit, Cambridge CB4 IXJ

A M Prentice, PHD, senior scientist

W A Coward, PHD, senior scientist

A E Black, BSC, chief research officer

R G Whitehead, PHD, director

Correspondence and requests for reprints to: Ms Livingstone.

Br.Med f 1990;300:708-12

\section{Accuracy of weighed dietary records in studies of diet and health /}

M B E E Livingstone, A M Prentice, J J Strain, W A Coward, A E 1 Black, M E Barker, P G McKenna,
R G Whitehead

Abstract

Objective - To provide an independent evaluation of seven day weighed dietary records, which are currently accepted as the most, accurate technique for assessing habitual dietary intake in studies investigating the links between diet and health.

Design-Subjects who had previously participated in the Northern Ireland diet and health study were reselected by stratified random sampling to represent the range of energy intakes in the study as assessed by the seven day weighed dietary record.

Setting-Northern Ireland.

Subjects-31 Free living adults (16 men and 15 women).

Main outcome measures-Energy intake as measured by the seven day weighed dietary record and total energy expenditure estimated concurrently by the doubly labelled water technique.

Results-Average recorded energy intakes were significantly lower than measured expenditure in the group overall $(9.66 \mathrm{MJ} /$ day $v 12.15 \mathrm{MJ} /$ day, $95 \%$ confidence interval 1.45 to $3.53 \mathrm{MJ} / \mathrm{day}$ ). Among those in the upper third of energy intakes the mean (SE) ratio of intake to expenditure was close to $1 \cdot 0$, indicating accurate records (men $1.01(0 \cdot 11)$, women $0.96(0.08))$. In the middle and lower thirds the ratios for men were only $0.74(0.05)$ and $0.70(0.07)$ respectively and for women $0.89(0.07)$ and 0.61 $(0 \cdot 07)$.

Conclusions - These results show a serious bias in reporting habitual energy intake. If substantiated they may have wide implications for the interpretation of many nutritional studies.

\section{Introduction}

Many studies of diet ånd health depend on accurate assessments of habitual intakes of food and nutrients in free living populations. Unfortunately, it has often been assumed that collecting such data is straightforward, and there has been a tendency to focus greater effort and resources on defining the correlates of health state with greater accuracy. Shortcomings in the methodology of dietary surveys may therefore have resulted in many potentially misleading data being published and may have contributed to the widespread confusion about the impact of diet on health. Recently there has been a growing awareness that measuring food intake may in fact be the most challenging problem faced in these studies. ${ }^{12}$

Difficulties in measuring food intake can be considered in three main categories: precision, random inaccuracy, and bias. The precision of dietary measurements can be readily assessed and thus allowed for when determining sample size or analysing results. ${ }^{3}$ Random inaccuracy may lead to false negative conclusions in epidemiological studies by reducing true associations but will not generate misleading correlations. Non-random errors, or bias, therefore emerge as the most serious problem. Although bias is recognised, its magnitude and direction has usually remained undetected as until recently there were no tech- 